\section{ORIGINAL RESEARCH}

\author{
H.J Kim \\ H.-J. Kim \\ Y.-D. Kim \\ Y.J. Yim \\ S.T. Kim \\ P. Jeon \\ K.H. Kim \\ H.S. Byun \\ H.J. Song
}

\title{
Solitary Fibrous Tumor of the Orbit: CT and MR Imaging Findings
}

BACKGROUND AND PURPOSE: Solitary fibrous tumor (SFT) is a rare spindle-cell neoplasm originating from mesenchymal fibroblast-like cells. The purpose of this study was to describe the CT and MR imaging features of SFTs in the orbit.

MATERIALS AND METHODS: We retrospectively reviewed CT and MR images in 6 patients $(2$ men and 4 women), aged 18 to 51 years, with SFT proved on histologic examination located in and around the orbit. All patients underwent CT (including dual-phase CT in 3), and MR imaging was obtained in 3 . We evaluated the imaging findings with emphasis on the location, size, margin, internal architecture, and pattern of enhancement of the lesion.

RESULTS: All 6 lesions were found as a solitary, well-defined mass, ranging in size from 18 to $30 \mathrm{~mm}$ (mean, $24 \mathrm{~mm}$ ). Three were located in the postseptal orbit, 2 in the lacrimal sac, and 1 on the lower eyelid. Compared with the cerebral cortex, all 3 lesions examined by MR imaging showed homogeneous isointense signal intensity on T1-weighted images and heterogeneous mixed isointense and hyperintense signal intensity on T2-weighted images. On visual inspection, all 6 lesions showed marked homogeneous $(n=4)$ or heterogeneous $(n=2)$ enhancement on postcontrast CT and MR images. In 3 patients examined with dual-phase CT, all lesions demonstrated rapid enhancement with early washout of contrast material.

CONCLUSION: SFT might be included in the differential diagnosis of soft tissue masses in the orbit, if one sees a markedly enhancing mass showing the similar characteristics to those of the internal carotid artery on postcontrast CT or MR images.

$\mathbf{S}_{\mathrm{p}}^{\mathrm{in}}$ ince the first report by Klemperer and Rabin ${ }^{1}$ in 1931 as a primary spindle-cell tumor of the pleura, solitary fibrous tumor (SFT) has been recognized as a distinctive, though rare, pathologic entity that most commonly arises from the pleura and peritoneum. Although once thought to be mesothelial in origin, SFT is now considered a tumor of mesenchymal fibroblast-like cell origin, and there has been an increasing incidence of the tumor to be found in the extrapleural, extraserosal sites such as the lung, liver, breast, and meninges. It can also arise in the extracranial head and neck region such as the orbit, sinonasal cavity, salivary gland, thyroid gland, upper respiratory tract, and deep cervical spaces. ${ }^{2-7}$

Since the first report of 2 cases of orbital SFT in $1994,{ }^{8}$ the orbit has become one of the common sites of the head and neck involved by the tumor, and more than 50 cases of orbital SFT have been reported mostly in the ophthalmologic and pathologic literature. ${ }^{9-21}$ To our knowledge, however, systematic analysis of the imaging features of orbital SFT has seldom been reported in the radiologic literature. The purpose of this study was to describe the characteristic CT and MR imaging findings of 6 cases of patients with SFT of the orbit proved on pathologic examination.

\section{Materials and Methods}

Between 1996 and 2006, review of medical records based on the electronic data base of our institution, approved by our institutional re-

Received September 9, 2007; accepted after revision November 11.

From the Departments of Radiology (H.J.K., H.-J.K., Y.J.Y., S.T.K., P.J., K.H.K., H.S.B.), Ophthalmology (Y.-D.K.), and Pathology (H.J.S.); Samsung Medical Center, Sungkyunkwan University School of Medicine, Seoul, Korea.

Please address correspondence to Hyung-Jin Kim, MD, Department of Radiology, Samsung Medical Center, Sungkyunkwan University School of Medicine, 50 Ilwon-Dong, KangnamKu, Seoul 135-710, Korea; e-mail: hyungkim@skku.edu

DOI 10.3174/ajnr.A0961 view board, revealed 6 patients with SFT proved on pathologic examination arising in the orbital and periorbital region. During the same period, we also found 6 cases of patients of intracranial SFT. However, no case of SFT could be found in the extracranial head and neck other than in the orbital region. We retrospectively reviewed CT $(n=6)$ and MR $(n=3)$ images obtained in these 6 patients, 2 of whom were previously reported in the literature. ${ }^{10}$ There were 2 men and 4 women, ranging in age from 18 to 51 years, with a mean age of 35 years.

The patients presented with slowly progressive, painless proptosis $(n=3)$ or palpable mass in the periocular area $(n=3)$, which had first been noticed 6 to 14 months earlier, with an average duration of 11 months. Two patients had a history of partial excision of the mass, after which the tumors recurred at 1 month and 6 years, respectively. All patients underwent complete excision of the tumor, and the diagnosis was confirmed by the characteristic histopathologic features and immunohistochemical studies showing a strong positive reaction for CD34. After the operation, all patients were in good health with no evidence of recurrent tumor during follow-up of 24 to 115 months (mean, 82 months).

All CT scans (6 patients) were obtained with a HiSpeed Advantage (GE Healthcare, Milwaukee, Wis) or Somatom Plus 4 (Siemens Medical Systems, Erlangen, Germany) to produce postcontrast axial and coronal images with 3-mm collimation. A total of $90 \mathrm{~mL}$ of iopamidol (Iopamiro 300; Bracco, Milan, Italy) or iopromide (Ultravist 300; Schering, Seoul, Korea) was administered into an antecubital vein at a rate of $3 \mathrm{~mL} / \mathrm{s}$ with a power injector. In the first 3 patients, postcontrast axial images were obtained at single phase with a scanning delay of 30 to 45 seconds. In the remaining 3 patients, postcontrast axial images were obtained at dual phases with scanning delays of 30 and 90 seconds, respectively. In all patients, delayed coronal scans were also obtained 4 to 6 minutes after the initiation of contrast material injection. In 5 patients, precontrast axial images were also obtained.

All MR examinations (3 patients) were performed on a 1.5T Signa 


\begin{tabular}{|c|c|c|c|c|c|c|c|c|c|c|}
\hline \multicolumn{11}{|c|}{ Clinical and imaging findings in six patients with solitary fibrous tumor of the orbit } \\
\hline \multirow{2}{*}{$\begin{array}{l}\text { Patient No./ } \\
\text { Age/Sex }\end{array}$} & \multirow{2}{*}{ Chief Complaint } & \multirow{2}{*}{$\begin{array}{c}\text { CT Scan/ } \\
\text { Dual-Phase } \\
\text { CT }\end{array}$} & \multirow{2}{*}{$\underset{\text { Image }}{\text { MR }}$} & \multirow[b]{2}{*}{ Location } & \multirow{2}{*}{$\begin{array}{l}\text { Size }^{*} \\
(\mathrm{~mm})\end{array}$} & \multirow[b]{2}{*}{ Margin } & \multirow{2}{*}{$\begin{array}{l}\text { Density on } \\
\text { Precontrast } \\
\text { CT Scant }\end{array}$} & \multicolumn{2}{|c|}{$\begin{array}{c}\text { Signal Intensity on MR } \\
\text { Imaging } \dagger\end{array}$} & \multirow{2}{*}{$\begin{array}{l}\text { Enhancement } \\
\text { Pattern/Degree }\end{array}$} \\
\hline & & & & & & & & T1WI & $\mathrm{T} 2 \mathrm{WI}$ & \\
\hline $1 / 26$ y/M & $\begin{array}{l}\text { Periocular mass } \\
\quad \text { for } 10 \text { months }\end{array}$ & Yes/No & No & Lacrimal sac & 30 & Well-defined & - & - & - & $\begin{array}{l}\text { Heterogeneous/ } \\
\text { marked }\end{array}$ \\
\hline $2 / 50 \mathrm{y} / \mathrm{F}$ & $\begin{array}{l}\text { Proptosis for } 8 \\
\text { months }\end{array}$ & Yes/Yes & Yes & $\begin{array}{l}\text { Postseptal } \\
\quad \text { extraconal }\end{array}$ & 30 & Well-defined & $\begin{array}{l}\text { Slightly } \\
\text { hyperdense }\end{array}$ & Isointense & $\begin{array}{l}\text { Mixed isointense } \\
\text { and hyperintense }\end{array}$ & $\begin{array}{l}\text { Homogeneous/ } \\
\text { marked }\end{array}$ \\
\hline $3 / 51$ y/F & $\begin{array}{l}\text { Periocular mass } \\
\text { for } 6 \text { months }\end{array}$ & Yes/Yes & No & Lacrimal sac & 18 & Well-defined & Isodense & - & - & $\begin{array}{l}\text { Homogeneous/ } \\
\text { marked }\end{array}$ \\
\hline $4 / 18 \mathrm{y} / \mathrm{F}$ & Proptosis for 2 y & Yes/No & Yes & $\begin{array}{l}\text { Postseptal } \\
\text { extraconal }\end{array}$ & 30 & Well-defined & Isodense & Isointense & $\begin{array}{l}\text { Mixed isointense } \\
\text { and hyperintense }\end{array}$ & $\begin{array}{l}\text { Heterogeneous/ } \\
\text { marked }\end{array}$ \\
\hline $5 / 24$ y/F & Proptosis for $1 \mathrm{y}$ & Yes/No & Yes & $\begin{array}{l}\text { Postseptal } \\
\text { intraconal }\end{array}$ & 18 & Well-defined & $\begin{array}{l}\text { Slightly } \\
\text { hyperdense }\end{array}$ & Isointense & $\begin{array}{l}\text { Mixed isointense } \\
\text { and hyperintense }\end{array}$ & $\begin{array}{l}\text { Homogeneous/ } \\
\text { marked }\end{array}$ \\
\hline $6 / 40$ y/M & $\begin{array}{l}\text { Periocular mass } \\
\text { for } 6 \text { months }\end{array}$ & Yes/Yes & No & $\begin{array}{l}\text { Lower } \\
\quad \text { eyelid }\end{array}$ & 20 & Well-defined & Isodense & - & - & $\begin{array}{l}\text { Homogeneous/ } \\
\text { marked }\end{array}$ \\
\hline
\end{tabular}

Note:-T1Wl indicates T1-weighted image; T2WI, T2-weighted image.

* Size was denoted as greatest diameter.

$\dagger$ Density and signal intensity of the tumor were compared with those of the cerebral gray matter.

Advantage Horizon (GE Healthcare) or Magnetom Vision (Siemens) scanner to produce precontrast and postcontrast T1-weighted spinecho images and T2-weighted fast spin-echo images with or without fat saturation. Images were obtained in at least 2 planes with 3 to 4-mm section thickness and 0 to 0.4 - $\mathrm{mm}$ intersection gap.

The CT and MR images were reviewed by a dedicated head and neck neuroradiologist and a general neuroradiologist in conference, both of whom have been practicing for more than 10 years. We evaluated the imaging findings with emphasis on the location, size, margin, internal architecture, and pattern and degree of enhancement of the lesion. The size of the lesion was measured at the greatest diameter of the lesion. The margin of the lesion was classified as well-defined and ill-defined. As for internal architecture, we compared the attenuation of the lesion on precontrast CT scans and the signal intensity of the lesion on T1- and T2-weighted MR images with those of the cerebral cortex. We also recorded the presence of if any calcifications within the lesion based on precontrast CT scans.

On postcontrast CT and MR images, the pattern of enhancement of the lesion was categorized as homogeneous or heterogeneous. The degree of enhancement of the lesion was subjectively assessed as being mild, moderate, and marked. As for the enhancement degree on CT scans, we relied on early-phase postcontrast axial images, viewed with the same window width $(300 \mathrm{HU})$ and level $(30 \mathrm{HU})$ in all patients. In 3 patients examined with dual-phase CT, we also measured the attenuation values on axial precontrast, early-phase, and late-phase CT scans as well as delayed coronal CT scans by placing the largest possible circular region of interest within the lesion. These values were plotted on the time-attenuation graph and compared with those of internal carotid artery, internal jugular vein, and medial rectus muscle.

\section{Results}

The CT and MR imaging features of 6 patients with orbital SFT are summarized in the Table. All lesions were found as a solitary, well-defined, ovoid mass, ranging in size from 18 to 30 $\mathrm{mm}$ (mean, $24 \mathrm{~mm}$ ). Three lesions were located in the postseptal orbit (Figs 1, 2), 2 in the lacrimal sac, and 1 on the lower eyelid (Fig 3). Although 2 of the 3 postseptal orbital lesions were found in the extraconal space at the superolateral (Fig 1) and superomedial aspect of the orbit, respectively, the remaining lesion was located in the intraconal space at the inferome- dial aspect of the orbit (Fig 2). Although the eyeball was displaced by the lesion in all 3 cases, true indentation of the eyeball by the lesion was demonstrated in only 1 case. In no case was there a significant change of the bony orbit. In both lesions of the lacrimal sac, CT also showed smooth expansion of the proximal nasolacrimal duct by the inferior growth of the tumor. Compared with the cerebral cortex, the attenuation of the lesion seen on precontrast CT scans obtained in 5 patients was isoattenuated in 3 and slightly hyperattenuated in 2 (Fig $1 A)$. There was no evidence of intralesional calcification demonstrated on precontrast CT scans. Compared with the cerebral cortex, all 3 lesions examined by MR imaging showed homogeneous isointense signal intensity on T1-weighted images (Figs $1 F, 2 B$ ) and heterogeneous mixed isointense and hyperintense signal intensity on T2-weighted images (Figs $1 G$, $2 C)$. In 1 of 3 lesions, signal-intensity void, tubular structures representing fast-flow vessels were found on T2-weighted and postcontrast T1-weighted MR images (Fig 2C-D).

On visual inspection, all 6 lesions showed marked homogeneous $(n=4)$ or heterogeneous $(n=2)$ enhancement on postcontrast CT and MR images (Figs $1 B-H, 2 A-D, 3 A$ ). In 3 patients examined with dual-phase CT, all lesions demonstrated rapid enhancement and early washout of contrast material (Figs 1, 3), and their time-attenuation curves revealed the very similar enhancing characteristics to those of the internal carotid artery (Fig 1E).

\section{Discussion}

Solitary fibrous tumor is a rare spindle-cell neoplasm that originates from mesenchymal fibroblast-like cells. Although most occur in the parietal or visceral pleura or peritoneum, they can arise from other extrapleural sites, including the mediastinum; lung; liver; breast; retroperitoneum; spine; meninges; and extracranial head and neck region such as the orbit, sinonasal cavity, salivary gland, thyroid gland, upper aerodigestive tract, infratemporal fossa, buccal space, and parapharyngeal space. ${ }^{2-7}$

On microscopic examination, SFT is a well-circumscribed, nonencapsulated tumor that shows a patternless arrangement of alternating hypercellular and hypocellular regions of spindle cells against a collagenous background of variable vascu- 

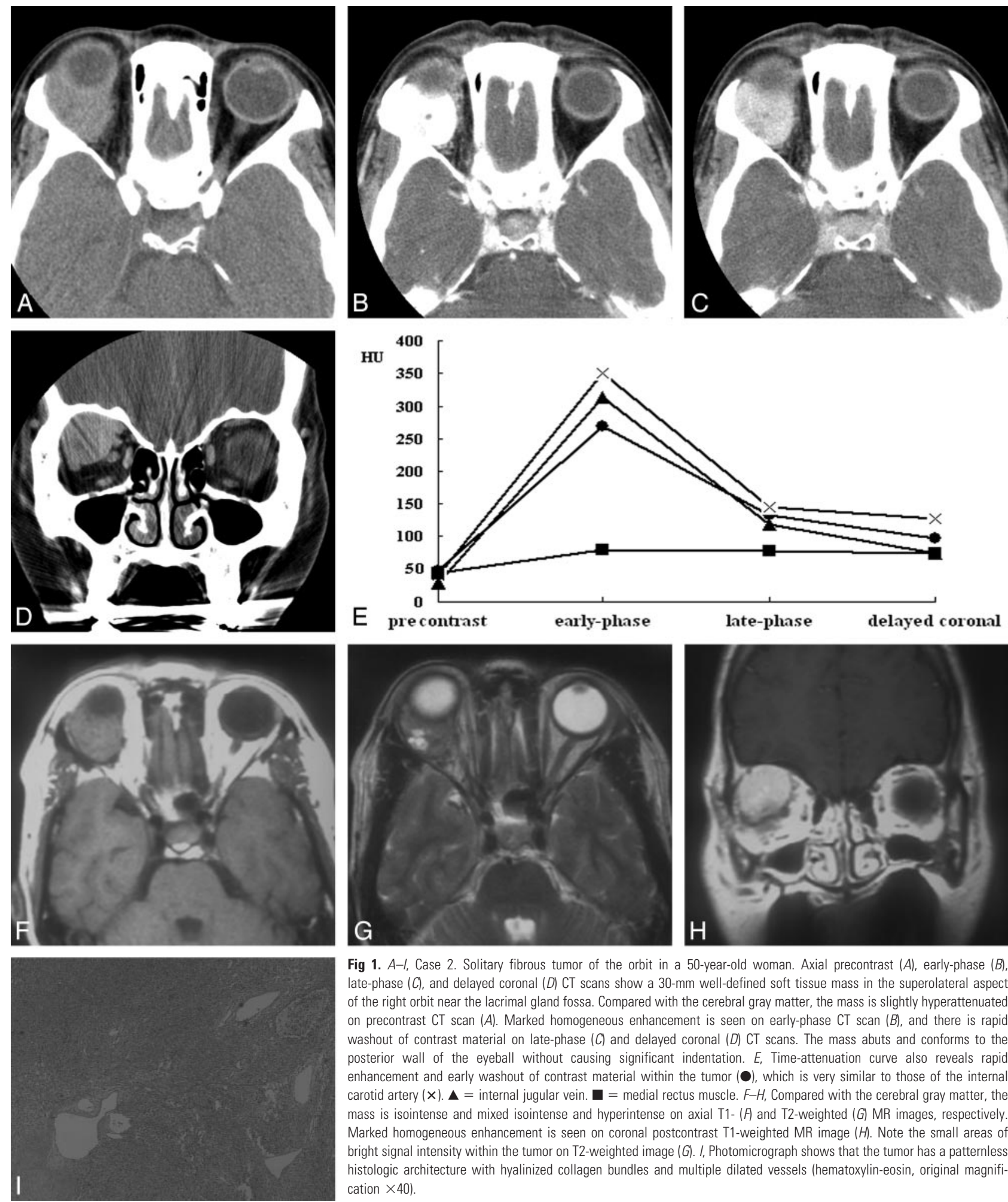

Fig 1. $A-I$, Case 2. Solitary fibrous tumor of the orbit in a 50-year-old woman. Axial precontrast $(A)$, early-phase $(B)$, late-phase $(C)$, and delayed coronal $(D) C T$ scans show a 30-mm well-defined soft tissue mass in the superolateral aspect of the right orbit near the lacrimal gland fossa. Compared with the cerebral gray matter, the mass is slightly hyperattenuated on precontrast CT scan (A). Marked homogeneous enhancement is seen on early-phase CT scan (B), and there is rapid washout of contrast material on late-phase $(C)$ and delayed coronal $(D)$ CT scans. The mass abuts and conforms to the posterior wall of the eyeball without causing significant indentation. E, Time-attenuation curve also reveals rapid enhancement and early washout of contrast material within the tumor $(\mathbf{)}$, which is very similar to those of the internal carotid artery $(\mathbf{x}) . \mathbf{\Delta}=$ internal jugular vein. $\mathbf{D}=$ medial rectus muscle. $F-H$, Compared with the cerebral gray matter, the mass is isointense and mixed isointense and hyperintense on axial T1- $(A$ and T2-weighted $(G)$ MR images, respectively. Marked homogeneous enhancement is seen on coronal postcontrast T1-weighted MR image $(H)$. Note the small areas of bright signal intensity within the tumor on T2-weighted image $(G)$. I, Photomicrograph shows that the tumor has a patternless histologic architecture with hyalinized collagen bundles and multiple dilated vessels (hematoxylin-eosin, original magnification $\times 40)$.

larity. In some cases, a focal hemangiopericytoma-like pattern of irregular branching vessels, fibrous histiocytoma-like storiform pattern, and synovial sarcomatous and neural-like pattern of palisading regional architecture are seen., ${ }^{4,1622}$ This variability on histologic examination often can lead to a mistaken diagnosis if limited tissue allows a single morphology to dominate the pathologic specimen.

The diagnosis of SFT can be solidified by the use of immu- nohistochemical analysis. ${ }^{3,15,16} \mathrm{CD} 34$, the hematopoietic progenitor cell antigen, is now believed to be the most important marker to diagnose SFT, and its diffuse and strong immunoreactivity has been demonstrated in $79 \%$ to $100 \%$ of cases. ${ }^{16}$ However, varying degrees of CD34 reactivity can also be present in other orbital tumors, such as hemangiopericytoma, fibrous histiocytoma, schwannoma, neurofibroma, fibrosarcoma, giant cell angiofibroma, and giant cell fibroblas- 

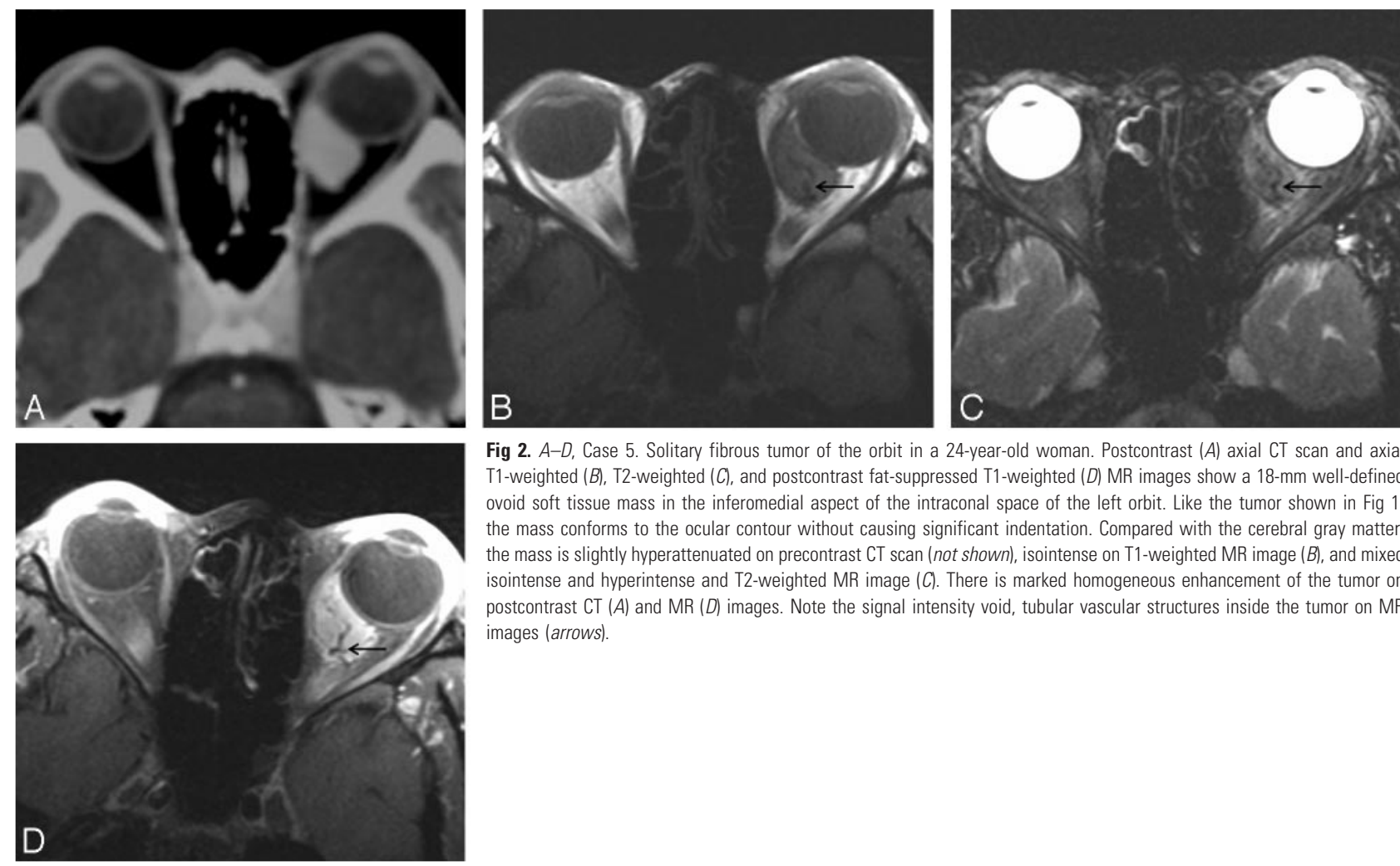

Fig 2. A-D, Case 5. Solitary fibrous tumor of the orbit in a 24-year-old woman. Postcontrast (A) axial CT scan and axial T1-weighted (B), T2-weighted (C), and postcontrast fat-suppressed T1-weighted (D) MR images show a 18-mm well-defined ovoid soft tissue mass in the inferomedial aspect of the intraconal space of the left orbit. Like the tumor shown in Fig 1 , the mass conforms to the ocular contour without causing significant indentation. Compared with the cerebral gray matter, the mass is slightly hyperattenuated on precontrast CT scan (not shown), isointense on T1-weighted MR image (B), and mixed isointense and hyperintense and T2-weighted MR image (C). There is marked homogeneous enhancement of the tumor on postcontrast $\mathrm{CT}(A)$ and $\mathrm{MR}(D)$ images. Note the signal intensity void, tubular vascular structures inside the tumor on MR images (arrows).
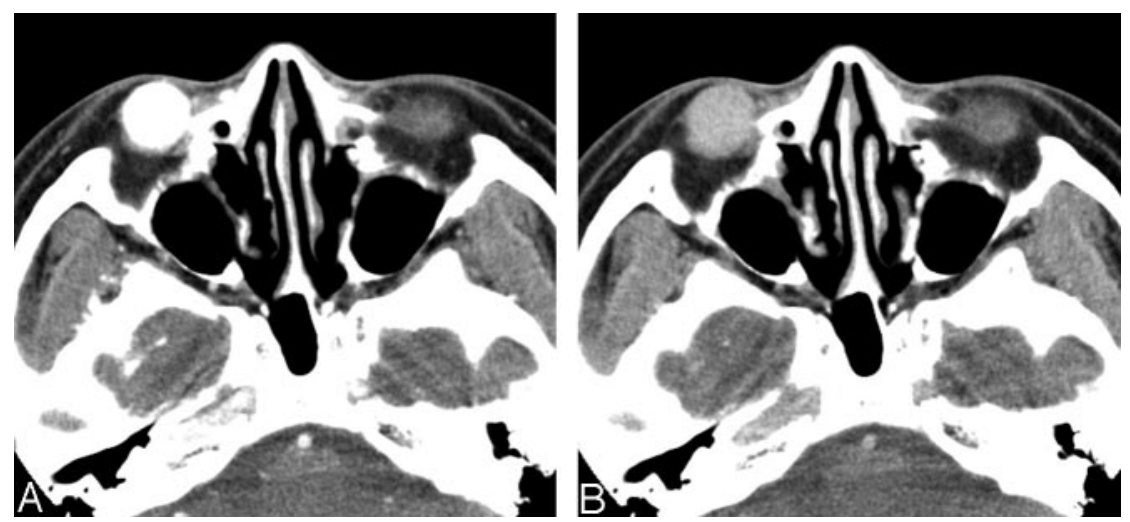

Fig 3. $A$ and $B$, Case 6. Solitary fibrous tumor of the lower eyelid in a 40 -year-old man. Axial early-phase $(A)$ and latephase $(B)$ CT scans show a 20-mm well-defined ovoid soft tissue mass on the right lower eyelid. Marked homogeneous enhancement is seen on early-phase CT scan $(A)$, followed by rapid washout of contrast material on late-phase CT scan $(B)$ toma. ${ }^{5,15,16}$ In addition to CD34, SFT is also immunoreactive for vimentin and B-cell lymphoma 2 (bcl-2) but negative for keratin, cytokeratin, epithelial membrane antigen, S-100 protein, smooth muscle actin, factor VIII-related antigen, and desmin. $^{15,16}$

The review of the literature reveals a recent trend of rather rapid accumulation of the number of orbital SFTs, and so far more than 50 cases of orbital SFT have been reported in the English-language literature. ${ }^{10-21}$ Bernardini et al ${ }^{15}$ questioned the rarity of orbital SFT. According to these authors, thanks to the widespread use of immunohistochemical studies, the number of orbital SFTs has rapidly been increasing after 1994 when the first orbital SFT was reported. Before that time, the diagnosis of orbital SFT based solely on the histopathologic findings was confused with other benign orbital tumors, such as fibrous histiocytoma and hemangiopericytoma. The authors suggested that SFT be considered relatively common and should be included in the differential diagnosis of orbital tumors in any age group. ${ }^{15}$
From a clinical standpoint, patients with orbital SFT usually present with slowly progressive unilateral exophthalmos or swelling or palpable mass of the eyelid or orbit, as shown in our series. A wide age range has been reported from 9 to 76 years without predilection to sex. ${ }^{14,16}$ In our study, patients' age ranged from 18 to 51 years (mean, 35 years), and there was predilection for women with the male-to-female ratio of 1:2. This demographic discrepancy between the studies seemed to be probably caused by a selection bias because of the limited number of cases. Although local excision is usually curative, orbital SFT has been reported to recur and may rarely metastasize. ${ }^{13}$ Although extremely rare, malignant orbital SFT has also been reported. ${ }^{14,16}$ Local recurrences are usually related to incomplete excision of the tumor and show the tendency to spread into the surrounding tissues and orbital bone, rendering complete secondary excision more difficult. ${ }^{10,15}$ There were 2 of 6 masses in this study that also recurred at 1 month and 6 years after partial excision of the mass, respectively. For- 
tunately, until now there is no evidence of recurrent disease after the second operation in both of the cases.

Various locations have been reported as the sites of orbital SFT and include the intraconal and extraconal spaces of the orbit, lacrimal gland, lacrimal sac, and eyelid. ${ }^{16,19}$ In our 6 cases of orbital SFT, 3 lesions were found in the various locations of the intraconal or extraconal space of the orbit, 2 in the lacrimal sac, and 1 on the lower eyelid. In both of the 2 lacrimal sac lesions that had previously been reported, ${ }^{10}$ the proximal nasolacrimal duct was also involved by the inferior growth of the tumor.

The reported radiologic appearances of head and neck SFT are rather nonspecific. ${ }^{5,7,11-25}$ Usually, the tumor is seen as a well-defined soft tissue mass with heterogeneously or homogeneously strong enhancement on CT and MR images. Occasional internal calcifications and necrosis have also been reported. ${ }^{23}$ Although remodeling of the adjacent bones may be seen in large, long-standing lesions, frank bone destruction is an exceptional finding that should prompt suspicion for a malignant tumor. ${ }^{5}$

Compared with the cerebral cortex or muscle, the signal intensity of SFT seen on MR images, in general, has been reported to be isointense on T1-weighted images and isointense to hypointense on T2-weighted images, reflecting fibrous tissue with high collagen content. 5,12,13,16,17,19,23,26 Sometimes, areas of hyperintense signal intensity are seen within the lesion on T2-weighted images, causing signal intensity heterogeneity on T2-weighted images. These areas of T2 hyperintensity are related to internal hemorrhage, cystic degeneration, or relatively fresh fibrosis. ${ }^{5,22,26}$ According to Kim et al, ${ }^{22}$ the signal intensity of SFT on T2-weighted MR images decreased as collagen content increased on microscopic examination. In this study, all 3 lesions examined by MR imaging showed isointense signal intensity to the cerebral cortex on T1-weighted images and mixed isointense and hyperintense signal intensity on T2-weighted images. We also believe that variations of the signal intensity on T2-weighted MR images would reflect the differences in the amount of cellular components, collagen, and fibroblasts as well as in the extent of degenerative change contained in the individual tumors.

Although not pathognomonic, homogeneous or heterogeneous-attenuated enhancement is reported to be the most prominent feature of SFT revealed with CT and MR imaging, which is attributed to high vascularity because of the prominent vascular channels within the tumor. ${ }^{5,16,21,23-25,27}$ In a likewise fashion, all 6 lesions in this study showed marked enhancement on postcontrast CT and MR images either homogeneously or heterogeneously. It is interesting to note that 1 of 3 lesions showed signal intensity-void, tubular structures on MR images (Fig $2 B-D$ ), which had not been reported by other investigators before. We believe that those structures represent fast-flow vessels within the tumor.

Enhancement of a certain tumor depends on various factors, including vascularity, capillary permeability, renal clearance, and composition of extracellular fluid. It can best be assessed radiologically by dynamic CT or MR imaging by evaluation of the chronologic changes of attenuation or signal intensity in the microcirculation of the tumor after injection of contrast material. Dual-phase helical CT can also be an alternative technique to dynamic CT for this purpose. ${ }^{28,29} \mathrm{With}$ the addition of delayed coronal scans, it can demonstrate a rough approximation of enhancing characteristics of the tumor. In this study, all 3 lesions examined with dual-phase CT demonstrated rapid, intense enhancement at early-phase axial scanning, followed by significant progressive washout of contrast material at late-phase axial and delayed-phase coronal scanning. Furthermore, the time-attenuation curves of orbital SFT in our series were very similar to those of the internal carotid artery in both enhancement degree and shape of the curve (Fig $1 E)$, which may be an additional clue to make the correct diagnosis.

On the basis of the aforementioned imaging characteristics of orbital SFT seen on CT and MR images, differential diagnosis for a highly vascular orbital lesion includes capillary hemangioma, cavernous hemangioma (venous malformation), varix, hemangiopericytoma, and giant cell angiofibroma. ${ }^{30,31}$ Unlike orbital SFTs, which predominantly affect adults, capillary hemangiomas are the most common orbital vascular tumors in infants. They typically go through a growth spurt during the first 6 months of life and then begin to involute. ${ }^{30}$ Although the enhancing characteristics on CT and MR images may be similar, orbital capillary hemangiomas can be differentiated from SFTs by the infiltrative nature with a nodular, irregular margin and hyperintensity containing fibrous septa and signal-intensity void vessels on T2-weighted MR images. Cavernous hemangiomas are the most common vascular lesions of the orbit in adults. Although controversy may still exist, they are believed not to be true vascular neoplasms but just hemodynamically isolated encapsulated venous malformations. ${ }^{30}$ On CT and MR images, cavernous hemangiomas are seen as a well-defined ovoid mass usually located at the intraconal space of the orbit. They can be differentiated from SFTs by hyperintensity containing fibrous septa on T2weighted MR images and the different enhancing characteristics showing delayed pooling of contrast material on dynamic studies. Although there have been different opinions about the pathogenesis, primary orbital varix is classically defined as a venous malformation in which there is abnormal dilation of 1 or more of the orbital veins, and the symptoms are related intimately to increased systemic venous pressure. Distended orbital varices frequently manifest as a well-defined elongated mass on CT and MR images. If there is no associated thrombosis or hemorrhage, they appear as a slightly hyperattenuated mass on CT and a hypointense mass on T1- and T2-weighted MR images. ${ }^{30}$ Contrast enhancement is variable and may be absent and is better seen on delayed postcontrast images. In cases of patients with associated thrombosis or hemorrhage, the attenuation and signal intensity can vary depending on the age of the clot. The most important imaging finding of orbital varices is demonstration of increase in size with increase in venous pressure with a Valsalva maneuver or on coronal scans with the neck extended. ${ }^{30}$ Hemangiopericytomas are highly vascular neoplasms of the somatic soft tissues. When they occur in the orbit, they tend to be more encapsulated than tumors elsewhere in the body. Orbital hemangiopericytomas may be the most difficult tumors to differentiate from orbital SFTs on imaging studies. On CT and MR images, they appear as a well-defined, markedly enhancing soft tissue mass that may be associated with bony erosion or infiltration into the adjacent structures. The signal intensity of hemangiopericyto- 
mas is isointense to gray matter on both T1- and T2-weighted MR images. ${ }^{30}$ Giant cell angiofibromas are rare benign spindle-cell neoplasms that show a predilection for the orbit and soft tissues of the head and neck. ${ }^{31}$ On CT and MR images, they can display the enhancing characteristics and signal intensity similar to those of orbital SFTs. Other orbital masses with less conspicuous contrast enhancement include schwannoma, neurofibroma, fibrous histiocytoma, lymphoma, pseudotumor, and metastasis. $^{32}$

\section{Conclusion}

Although SFT is known as a relatively rare soft tissue tumor arising in the orbit, by virtue of the widespread use of immunohistochemical staining, its incidence is now steadily increasing. Although the distinction from hemangiopericytoma and giant cell angiofibroma would still be difficult, we believe that SFT might be put in the first lines of a differential list of the orbital mass, if one sees a markedly enhancing mass showing the similar characteristics of the internal carotid artery on postcontrast CT or MR images.

\section{References}

1. Klemperer P, Rabin CB. Primary neoplasms of the pleura. A report of five cases. Arch Pathol 1931;11:385-412

2. Goodlad JR, Fletcher CD. Solitary fibrous tumour arising at unusual sites: analysis of a series. Histopathology 1991;19:515-22

3. Suster S, Nascimento AF, Miettinen M, et al. Solitary fibrous tumors of soft tissue. A clinicopathologic and immunohistochemical study of 12 cases. Am J Surg Pathol 1995;19:1257-66

4. Chan JK. Solitary fibrous tumour-everywhere, and a diagnosis in vogue. Histopathology 1997;31:568-76

5. Ganly I, Patel SG, Stambuk HE, et al. Solitary fibrous tumors of the head and neck: a clinicopathologic and radiologic review. Arch Otolaryngol Head Neck Surg 2006;132:517-25

6. Rayappa CS, McArthur PD, Gangopadhyay K, et al. Solitary fibrous tumour of the infratemporal fossa. J Laryngol Otol 1996;110:594-97

7. Sato J, Asakura K, Yokoyama Y, et al. Solitary fibrous tumor of the parotid gland extending to the parapharyngeal space. Eur Arch Otorhinolaryngol 1998;255:18-21

8. Westra WH, Gerald W, Rosai J. Solitary fibrous tumor. Consistent CD34 immunoreactivity and occurrence in the orbit. Am J Surg Pathol 1994;18:992-98

9. Dorfman DM, To K, Dickersin GR, et al. Solitary fibrous tumor of the orbit. Am J Surg Pathol 1994;18:281-87

10. Woo KI, Suh Y-L, Kim Y-D. Solitary fibrous tumor of the lacrimal sac. Ophthal Plast Reconstr Surg 1999;15:450-53
11. Festa S, Lee HJ, Langer P, et al. Solitary fibrous tumor of the orbit: CT and pathologic correlation. Neuroradiology 1999;41:52-54

12. Kim HY, Lee SY, Kang SJ, et al. Solitary fibrous tumor of the orbit: a poorlyrecognized orbital lesion. Acta Ophthalmol Scand 1999;77:704-08

13. Hayashi S, Kurihara H, Hirato J, et al. Solitary fibrous tumor of the orbit with extraorbital extension: case report. Neurosurgery 2001;49:1241-45

14. Polito E, Tosi GM, Toti $P$, et al. Orbital solitary fibrous tumor with aggressive behaviour. Three cases and review of the literature. Graefes Arch Clin Exp Ophthalmol 2002;240:570-74

15. Bernardini FP, de Conciliis C, Schneider S, et al. Solitary fibrous tumor of the orbit: is it rare? Report of a case series and review of the literature. Ophthalmology 2003;110:1442-48

16. Krishnakumar S, Subramanian N, Mohan ER, et al. Solitary fibrous tumor of the orbit: a clinicopathologic study of six cases with review of the literature. Surv Ophthalmol 2003;48:544-54

17. Johnson TE, Onofrey CB, Ehlies FJ. Echography as a useful adjunct in the diagnosis of orbital solitary fibrous tumor. Ophthal Plast Reconstr Surg 2003; 19:68-74

18. Galie M, Tieghi R, Cavazzini L, et al. Solitary fibrous tumor of the orbit: a case report. Int J Oral Maxillofac Surg 2005;34:331-33

19. Romer M, Bode B, Schuknecht B, et al. Solitary fibrous tumor of the orbit - two cases and a review of the literature. Eur Arch Otorhinolaryngol 2005;262:81-88

20. Cerda-Nicolas M, Lopez-Gines C, Gil-Benso R, et al. Solitary fibrous tumor of the orbit: morphological cytogenic and molecular features. Neuropathology 2006;26:557-63

21. Meyer D, Riley F. Solitary fibrous tumor of the orbit: a clinicopathologic entity that warrants both a heightened awareness and an atraumatic surgical removal technique. Orbit 2006;25:45-50

22. Kim HJ, Lee HK, Seo JJ, et al. MR imaging of solitary fibrous tumors in the head and neck. Korean J Radiol 2005;6:136-42

23. Kim TA, Brunberg JA, Pearson JP, et al. Solitary fibrous tumor of the paranasa sinuses: CT and MR appearance. AJNR Am J Neuroradiol 1996;17:1767-72

24. Shin JH, Sung IY, Suh JH, et al. Solitary fibrous tumor in the buccal space: MR findings with pathologic correlation. AJNR Am J Neuroradiol 2001;22:1890-92

25. Jeong AK, Lee HK, Kim SY, et al. Solitary fibrous tumor of the parapharyngeal space: MR imaging findings. AJNR Am J Neuroradiol 2002;23:473-75

26. Dunfee BL, Sakai O, Spiegel JH, et al. Solitary fibrous tumor of the buccal space. AJNR Am J Neuroradiol 2005;26:2114-16

27. Tateishi U, Nishihara H, Morikawa T, et al. Solitary fibrous tumor of the pleura: MR appearance and enhancement pattern. J Comput Assist Tomogr 2002;26:174-79

28. Choi DS, Na DG, Byun HS, et al. Salivary gland tumors: evaluation with twophase helical CT. Radiology 2000;214:231-26

29. Moon W-J, Na DG, Ryoo JW, et al. Orbital lymphoma and subacute or chronic inflammatory pseudotumor: differentiation with two-phase helical computed tomography. J Comput Assist Tomogr 2003;27:510-16

30. Bilaniuk LT. Orbital vascular lesions: role of imaging. Radiol Clin North Am 1999;37:169-83

31. Keyserling H, Peterson K, Camacho D, et al. Giant cell angiofibroma of the orbit. AJNR Am J Neuroradiol 2004;25:1266-68

32. Dalley RW. Fibrous histiocytoma and fibrous tissue tumors of the orbit. Radiol Clin North Am 1999;37:185-94 